\title{
Signal Transduction, Pharmacological Properties, and Expression Patterns of Two Rat Metabotropic Glutamate Receptors, mGluR3 and mGluR4
}

\author{
Yasuto Tanabe, ${ }^{1}$ Akinori Nomura, ${ }^{1}$ Masayuki Masu, ${ }^{1}$ Ryuichi Shigemoto, ${ }^{2}$ Noboru Mizuno, ${ }^{2}$ and Shigetada \\ Nakanishi' \\ ${ }^{1}$ Institute for Immunology and the ${ }^{2}$ Department of Morphological Brain Science, Kyoto University Faculty of Medicine, \\ Kyoto 606, Japan
}

The metabotropic glutamate receptors are coupled to intracellular signal transduction via G-proteins and consist of a family of at least five different subtypes, termed mGluR1mGluR5. We studied the signal transduction mechanism and pharmacological characteristics of the rat mGluR3 and mGluR4 subtypes in Chinese hamster ovary cells permanently expressing the cloned receptors. Both mGluR3 and mGluR4 inhibit the forskolin-stimulated accumulation of intracellular cAMP formation in response to agonist interaction. Consistent with the high degree of sequence similarity to mGluR2, mGluR3 closely resembles mGluR2 in its agonist selectivity; the potency rank order of agonists is L-glutamate $>$ trans-1-aminocyclopentane-1,3-dicarboxylate > ibotenate $>$ quisqualate. mGluR4 is totally different in its agonist specificity from any other member of the metabotropic receptors. This receptor potently reacts with L-2-amino-4phosphonobutyrate (L-AP4) in a stereo-selective manner and moderately responds to $L$-serine- $O$-phosphate. MGluR4 thus corresponds well to the putative L-AP4 receptor characterized from brain preparations. Blot and in situ hybridization analyses indicated that both mRNAs are widely distributed in the rat brain. mGluR3 mRNA is highly expressed in neuronal cells of the cerebral cortex and the caudate-putamen, and in granule cells of the hippocampal dentate gyrus. The expression pattern of mGluR4 mRNA is more restricted, and this expression is prominent in the cerebellum, olfactory bulb, and thalamus. Furthermore, the mGluR3 mRNA, unlike the other mRNAs for the metabotropic receptors, is highly expressed in glial cells throughout the brain regions. The metabotropic glutamate receptor subtypes can thus be classified into three subgroups according to the similarity in their amino acid sequences, signal transduction, and agonist selectivity: mGluR1/mGluR5, mGluR2/mGluR3, and mGluR4. The mRNAs for the individual receptor subtypes, however, show overlapping but distinct patterns of expression in the rat CNS.

\footnotetext{
Received July 30, 1992; revised Oct. 2, 1992; accepted Oct. 8, 1992.

We are grateful to Akira Uesugi for photographic assistance. This work was supported in part by research grants from the Ministry of Education, Science and Culture of Japan, the Ministry of Health and Welfare of Japan, the Uehara Memorial Foundation, and the Senri Life Science Foundation.

Correspondence should be addressed to Shigetada Nakanishi, Institute for Immunology, Kyoto University Faculty of Medicine, Yoshida, Sakyo-ku, Kyoto 606, Japan.

Copyright (C) 1993 Society for Neuroscience $0270-6474 / 93 / 131372-07 \$ 05.00 / 0$
}

[Key words: metabotropic glutamate receptor, cDNA clone, DNA transfection, signal transduction, agonist selectivity, in situ hybridization]

L-Glutamate acts as a major excitatory neurotransmitter and plays an important role in neuronal plasticity and neurotoxicity in the CNS (Monaghan et al., 1989; Watkins et al., 1990). Glutamate neurotransmission is thus thought to be involved in many integrative brain functions including memory acquisition and learning, and also in some neurodegenerative disorders such as stroke and epilepsy (Collingridge and Singer, 1990; Meldrum and Garthwaite, 1990). The disparate functions of glutamate neurotransmission are reflected in the presence of multiple receptors that can be categorized into two distinct groups termed ionotropic and metabotropic receptors (mGluRs) (Monaghan et al., 1989). The ionotropic receptors, consisting of the NMDA receptors and AMPA/kainate receptors, contain cation-specific ion channels and share fundamental features with other ligandgated ion channels (Hollmann et al., 1989; Monaghan et al., 1989; Moriyoshi et al., 1991). The metabotropic receptors modulate the production of intracellular second messengers and belong to the family of G-protein-coupled receptors (Schoepp et al., 1990; Récasens et al., 1991). An additional and novel receptor termed L-AP4 (L-2-amino-4-phosphonobutyrate) receptor has been identified through the actions of this compound on certain glutamate-using synapses (Monaghan et al., 1989). The L-AP4 receptor has been shown to suppress synaptic glutamate neurotransmission and appears to represent an autoreceptor (Cotman et al., 1986; Forsythe and Clements, 1990; Baskys and Malenka, 1991). However, the molecular nature of the L-AP4 receptor remained to be elucidated.

Recently, we isolated cDNA clones for five different subtypes of the rat mGluR family (mGluR1-mGluR5) by molecular screening of a rat brain cDNA library (Masu et al., 1991; Abe et al., 1992; 'Tanabe et al., 1992). The mGluR family possesses a large extracellular domain preceding the seven putative transmembrane scgments and sharcs a high scquence similarity among the five different subtypes (Houamed et al., 1991; Masu et al., 1991; Abe et al., 1992; Tanabe et al., 1992). These subtypes can be divided further into three subgroups according to their sequence similarities: mGluR1/mGluR5, mGluR2/mGluR3, and mGluR4 (Abe et al., 1992; Tanabe et al., 1992). Consistent with the sequence similarity, both mGluR 1 and mGluR5 are coupled to the stimulation of phosphatidylinositol (PI) hydrolysis/ $\mathrm{Ca}^{2+}$ signal transduction and show strong resemblance in their agonist 

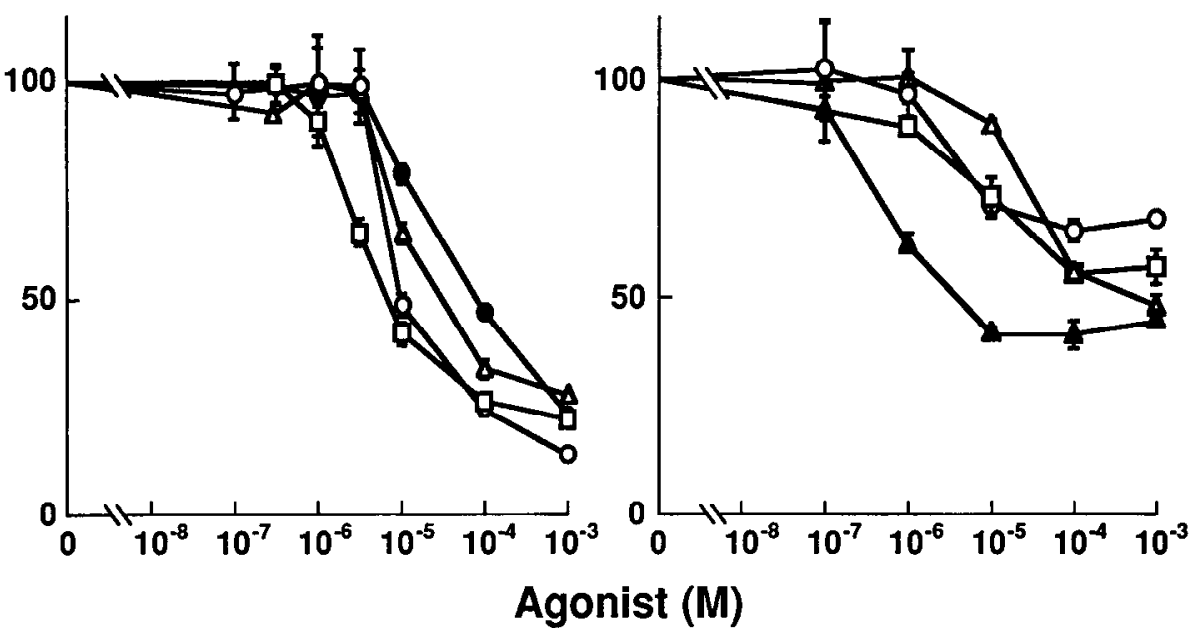

Figure 1. Dose-response curves of agonists in inhibition of forskolin-stimulated cAMP accumulation in cells stably expressing mGluR3 $(a)$ and mGluR4 (b). Agonists added to forskolin-treated cells are as follows: in $a, \square, \mathrm{L}$-glutamate; $\mathrm{O}, \mathrm{tACPD} ; \triangle$, ibotenate; $\boldsymbol{\theta}$, quisqualate; in $b, \triangle, \mathrm{L}-\mathrm{AP} 4 ; \square, \mathrm{L}$-glutamate; O, L-serine- $O$-phosphate; $\triangle$, D-AP4. Intracellular cAMP levels in cells treated and untreated with $10 \mu \mathrm{M}$ forskolin were 233 \pm 8.9 and $7.2 \pm 0.4 \mathrm{pmol} /$ well in $a$, respectively, and $239 \pm 20$ and $8.4 \pm$ $1.0 \mathrm{pmol} /$ well in $b$, respectively. The cAMP levels in forskolin-treated cells are taken as $100 \%$. Each point represents the mean \pm SEM of at least two separate experiments done in triplicate.

selectivity (Abe et al., 1992; Aramori and Nakanishi, 1992). mGluR2, on the other hand, is linked to the inhibitory cAMP cascade and exhibits an agonist selectivity different from that of $\mathrm{mGluR1/mGluR5}$ (Tanabe et al., 1992). However, neither the precise signal transduction nor the agonist selectivity of mGluR3 or mGluR4 has yet been characterized. In this study, we stably expressed mGluR 3 and mGluR 4 by DNA transfection into Chinese hamster ovary ( $\mathrm{CHO}$ ) cells and investigated the intracellular signal transduction mechanisms and pharmacological characteristics of these receptor subtypes. We also analyzed expression patterns of the mRNAs for mGluR3 and mGluR4 by RNA blot and in situ hybridization. The results demonstrated that both subtypes are linked to the inhibitory cAMP cascade. However, mGluR4 is totally different from other members of mGluRs in agonist selectivity and reacts with L-AP4 with a high potency that is one order more effective than L-glutamate. Furthermore, the mGluR3 mRNA, unlike other mRNAs of the mGluR subtypes, has been found to be highly expressed in both neuronal and glial cells.

\section{Materials and Methods}

Materials. L-AP4, D-AP4, L-serine- $O$-phosphate, quisqualate, and tACPD (trans-1-aminocyclopentane-1,3-dicarboxylate) were purchased from Tocris Neuramin. D-AP4 was more than $98 \%$ enantiomerically pure but may have contained a trace amount of L-AP4 (less than $2 \%$ ). All other compounds were reagent grade and were obtained as described previously (Tanabe et al., 1992).

Receptor expression in CHO cells and cAMP measurements. The cDNA clones for mGluR3 (pmGR3) and for mGluR4 (pmGR4) were described previously (Tanabe et al., 1992). The AT-rich sequence in the $3^{\prime}$ noncoding region of pmGR3 was removed by digestion with PfIMI, whose site was 65 base pairs (bp) downstream of the stop codon. The resulting 2.9 kilobase pair (kbp) ClaI-PflMI fragment of pmGR3 and the $3.9 \mathrm{kbp}$ EcoRI fragment of pmGR4 were inserted individually into a eukaryotic expression vector (pdKCR-dhfr) containing the mouse dihydrofolate reductase gene as a selective marker (Tanabe et al., 1992). These plasmids were transfected into $\mathrm{CHO}$ cells deficient in dihydrofolate reductase activity (CHO-dhfr ${ }^{-}$) (Urlaub and Chasin, 1980) by the calcium phosphate method (Graham and van der Eb, 1973). Cell populations expressing mGluR 3 or mGluR4 together with dihydrofolate reductase were selected in Dulbecco's modified Eagle's medium lacking L-glutamate, ribonucleosides, and deoxyribonucleosides, and containing a reduced concentration ( $2 \mathrm{mM}$ ) of L-glutamine (Tanabe et al., 1992). Clonal cell lines expressing high levels of mGluR3 or mGluR4 were identified by measuring the glutamate-induced inhibition of the forskolin-stimulated cAMP accumulation. For the measurement of cAMP levels, a clonal cell line expressing mGluR 3 or mGluR 4 was seeded individually in 12-well plates at a density of $1.5 \times 10^{5}$ cells/well and grown for $3 \mathrm{~d}$. After $20 \mathrm{~min}$ preincubation in phosphate-buffered saline (PBS) containing $1 \mathrm{~mm} 3$-isobutyl-1-methylxanthine (IBMX) at $37^{\circ} \mathrm{C}$, the cells were incubated with fresh PBS containing $10 \mu \mathrm{M}$ forskolin, $1 \mathrm{mM}$ IBMX, and test agents for $10 \mathrm{~min}$. The medium was aspirated, and the reaction was stopped by the addition of 5\% trichloroacetic acid. cAMP levels were measured by the RIA kit (Amersham). For pertussis toxin (PTX) treatment, cells were preincubated with various concentrations of PTX for $11 \mathrm{hr}$ at $37^{\circ} \mathrm{C}$. Each experiment was carried out at least twice in triplicate.

RNA blot and in situ hybridization analyses. RNA blot analysis was carried out by using $10 \mu \mathrm{g}$ of total RNAs isolated from various regions of the brain as described previously (Masu et al., 1991). The cDNA probe used was the $877 \mathrm{bp}$ PstI fragment of pmGR3 and the $1263 \mathrm{bp}$ Smal fragment of pmGR4. In situ hybridization was performed as previously described (Masu et al., 1991). Briefly, ${ }^{35}$ S-labeled antisense riboprobe corresponding to the 1464 bp HincII-XbaI or 648 bp EcoT14I fragment of pmGR3 or the $1230 \mathrm{bp} \mathrm{Xhol-PstI} \mathrm{or} 568 \mathrm{bp}$ PstI fragment of pmGR4 was transcribed and hybridized as described previously (Tanabe et al., 1992). Sections were exposed to $\beta$ max-film (Amersham) for 2 weeks or dipped in NTB2 emulsion (Kodak) diluted $1: 1$ with distilled water, developed after a 4 week exposure, and counterstained with cresyl violet. Control hybridization experiments were carried out in adjacent sections by using the same riboprobe in the presence of an excess of unlabeled probe.

\section{Results}

Signal transduction and agonist profiles of $m G l u R 3$ and mGluR4

To investigate the pharmacological profiles and signal transduction of mGluR3 and mGluR4, we stably expressed individual cDNA clones encoding these receptor subtypes in mammalian CHO cells. A mouse dihydrofolate reductase gene was used as a selective marker gene that allowed receptor-expressing cells to grow in a medium lacking ribonucleosides and deoxyribonucleosides. We also removed L-glutamate and reduced the concentration of L-glutamine in the culture medium to avoid the possible constitutive activation of these receptors by L-glutamate. Through this procedure, we succeeded in obtaining several cell lines stably expressing mGluR 3 and mGluR4. Because mGluR3 shows a high degree $(\sim 70 \%)$ of sequence similarity to mGluR2 that is coupled to the inhibitory cAMP cascade (Tan- 


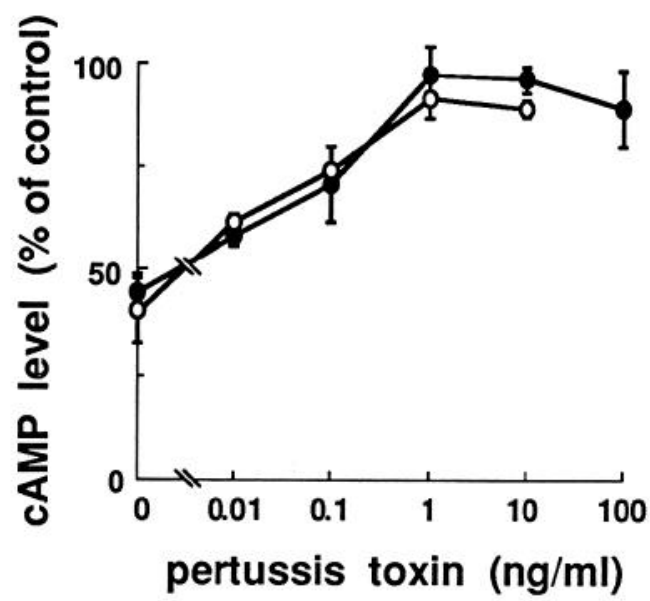

Figure 2. Effects of PTX on agonist-mediated inhibition of forskolinstimulated cAMP accumulation. mGluR3-expressing cells $(O)$ and mGluR4-expressing cells $(\bullet)$ were pretreated with various concentrations of PTX for $11 \mathrm{hr}$. Forskolin-stimulated cAMP levels were determined with or without addition of $100 \mu \mathrm{M}$ L-glutamaie for mGluR3 and with or without addition of $100 \mu \mathrm{M} \mathrm{L}-\mathrm{AP} 4$ for mGluR4. The levels obtained without addition of L-glutamate or L-AP4 are taken as $100 \%$ at each concentration of PTX indicated. Each point represents the mean \pm SEM of at least two separate experiments done in triplicate.

abe et al., 1992), we examined inhibitory effects of L-glutamate on the forskolin-stimulated cAMP accumulation in mGluR3expressing cells. As expected, mGluR3 showed efficient L-glutamate-mediated inhibition of the forskolin-stimulated cAMP formation (Fig. 1a). Similarly, L-glutamate added to mGluR4expressing cells resulted in significant inhibition of the forskolininduced cAMP accumulation (Fig. $1 b$ ). This inhibition, however, did not extend beyond about $50 \%$ of the maximally stimulated levels even by the addition of higher concentrations of L-glutamate. Because this partial inhibition was consistently observed in several independent mGluR4-expressing cell lines, this inhibition pattern probably represents a feature characteristic of the signal transduction mediated by mGluR4. No L-glutamate-mediated inhibition of the forskolin-stimulated cAMP formation was observed in untransfected control cells or those transfected with the vector DNA alone (data not shown). Furthermore, no appreciable stimulation of PI hydrolysis, cAMP formation, or arachidonic acid release was induced by the addition of L-glutamate in either mGluR3- or mGluR4-expressing cells (data not shown). Thus, it can be concluded that both mGluR 3 and mGluR4 subtypes are coupled to the inhibitory cAMP cascade.

We determined dose-response curves of various agonists for the inhibition of the forskolin-stimulated cAMP accumulation in mGluR3-expressing cells (Fig. 1a). L-glutamate, tACPD, ibotenate, and quisqualate were effective in inhibiting the cAMP accumulation in this order of agonists. Thus, the rank order of these compounds was in complete agreement with that determined for mGluR2 (Tanabe et al., 1992). The effective concentrations of half-maximal response $\left(\mathrm{EC}_{50}\right)$ of the above compounds were calculated to be $3,8,10$, and $40 \mu \mathrm{M}$, respectively. These values were also very similar to those reported for mGluR2 (Tanabe et al., 1992). NMDA, kainate, AMPA, and L-AP4 had virtually no effects on the signal transduction of mGluR 3 in receptor-expressing cells. Thus, mGluR3 closely resembles mGluR2 in the signal transduction and agonist selectivity.

Because mGluR4 was found to be linked to the inhibitory cAMP cascade, we determined an agonist profile of mGluR4 a

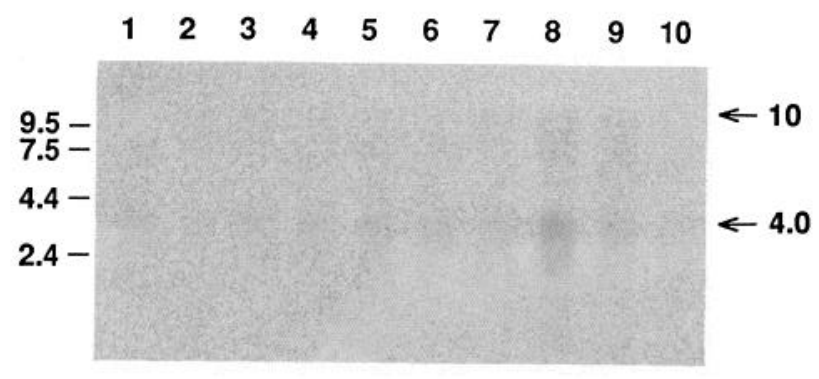

b

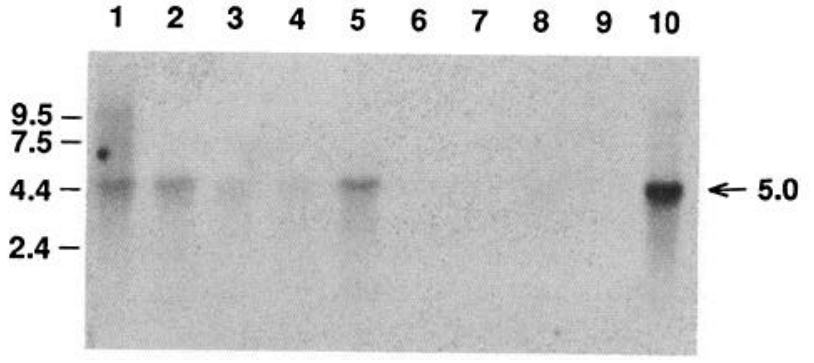

Figure 3. RNA blot hybridization analysis of $\operatorname{mGluR} 3(a)$ and mGluR4 (b). Total RNAs analyzed are as follows: 1 , whole brain; 2 , olfactory bulb; 3 , medulla/pons; 4 , midbrain; 5 , thalamus; 6 , hypothalamus; 7 , hippocampus; 8 , striatum; 9 , cerebral cortex; 10 , cerebellum. The size marker (kilonucleotides) used was the RNA ladder (Bethesda Research Labs).

by measuring cAMP levels after application of various compounds to forskolin-treated mGluR4-expressing cells (Fig. 1b). The cAMP accumulation was reduced by $L$-glutamate in a dosedependent manner with an $\mathrm{EC}_{50}$ value of $5 \mu \mathrm{M}$. Notably, L-AP4 more effectively inhibited the forskolin-stimulated cAMP accumulation, and this potency with an $\mathrm{EC}_{50}$ value of $0.5 \mu \mathrm{M}$ was one order higher than that of L-glutamate. L-Serine- $O$-phosphate was also an effective agonist with an $\mathrm{EC}_{50}$ value of $4 \mu \mathrm{M}$, although the extent of this inhibition was less than those observed for L-AP4 and L-glutamate. D-AP4, an enantiomer of L-AP4, evoked inhibitory responses at higher concentrations. However, the D-AP4 available for our experiments was not entirely pure and may have contained a trace amount of L-AP4. Because L-AP4 and D-AP4 showed about 2 orders of magnitude difference in the effective concentrations, it is feasible that the effect of D-AP4 arises from a small amount of L-AP4 in our D-AP4 preparation rather than reflecting its intrinsic activity. $\mathrm{AACPD}$, quisqualate, and D,L-2-amino-3-phosphonopropionate evoked slight inhibition (10-20\%) of the cAMP formation at the concentration of $100 \mu \mathrm{M}$. However, this inhibition was variable among the different experiments, and was also observed in untransfected control cells. Thus, the agonist activity of these compounds could not be evaluated as being statistically significant. NMDA, kainate, ibotenate, and AMPA did not display any inhibitory activity at $100 \mu \mathrm{M}$ each. Thus, the results presented here demonstrated that mGluR4 is clearly distinguishable from other members of the mGluR family by its characteristic agonist selectivity.

PTX catalyzes the ADP-ribosylation of some G-proteins, thus uncoupling them from their linked receptors (Gilman, 1984; Ui, 1984). The PTX-sensitive $G$-proteins include $G_{i}$ linked to the inhibitory cAMP cascade, $\mathrm{G}_{o}$, and a certain type of $\mathrm{G}_{p}$ that may be coupled to PI hydrolysis (Gilman, 1984; Ui, 1984). To address the coupling of mGluR 3 and mGluR4 to G-proteins, we investigated the effects of PTX on mGluR3- and mGluR4-me- 

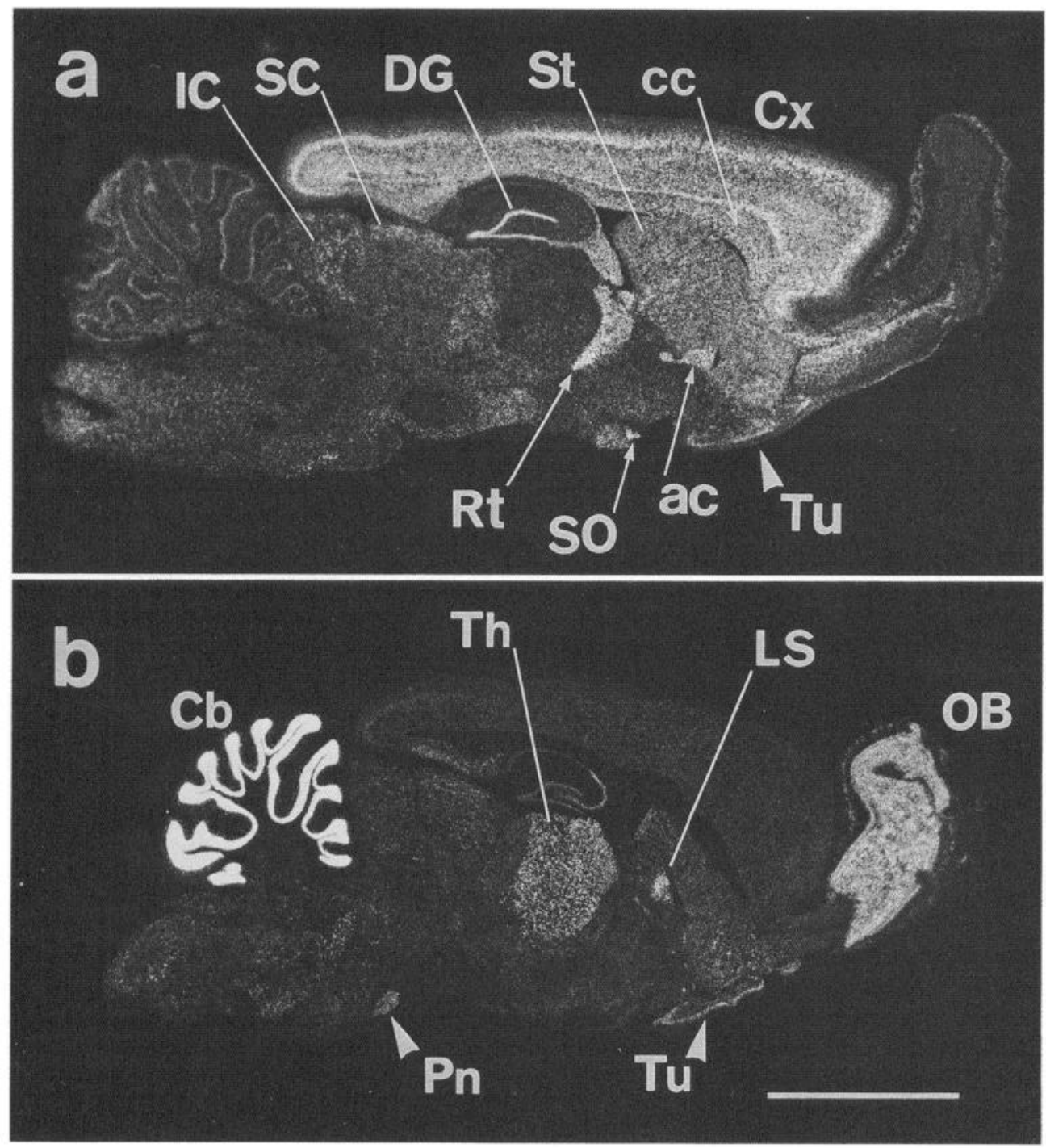

Figure 4. Localization of mGluR3 mRNA $(a)$ and mGluR4 mRNA $(b)$ in the adult rat brain by in situ hybridization. Negative film images of sagittal sections are shown. $I C$, inferior colliculus; $S C$, superior colliculus; $D G$, dentate gyrus; $S t$, striatum; $c c$, corpus callosum; $C x$, cerebral cortex; $R t$, thalamic reticular nucleus; $S O$, supraoptic nucleus; $a c$, anterior commissure; $T u$, olfactory tubercle; $C b$, cerebellar cortex; $P n$, pontine nucleus; $T h$, thalamus; $L S$, lateral septum; $O B$, main olfactory bulb. Scale bar, $5 \mathrm{~mm}$. diated inhibition of the cAMP accumulation (Fig. 2). When mGluR3- and mGluR4-expressing cells were pretreated with PTX prior to addition of forskolin and an agonist (L-glutamate for mGluR3 and L-AP4 for mGluR4), the agonist-mediated inhibition of cAMP accumulation was reduced in a dose-dependent manner and was completely abolished at $1 \mathrm{ng}$ of PTX per milliliter of medium in both cases. Thus, the agonist responses in both receptors are mediated by a PTX-sensitive $\mathrm{G}_{i}$ protein.

\section{Expression patterns of $m G l u R 3$ and $m G l u R 4 m R N A s$}

The distribution of mGluR3 and mGluR4 transcripts in the adult rat brain was examined by RNA blot and in situ hybridization analyses. Blot hybridization analysis of $\mathrm{mGluR} 3 \mathrm{mRNA}$ revealed a wide distribution of an mRNA of $\sim 4.0 \mathrm{~kb}$ throughout the brain regions (Fig. $3 a$ ). Additionally, a minor band corresponding to an mRNA size of $\sim 10 \mathrm{~kb}$ was seen in all regions examined. Blot hybridization analysis of mGluR4 mRNA yielded a band with an estimated mRNA size of $\sim 5.0 \mathrm{~kb}$ (Fig. $3 b$ ). A minor band with an mRNA size of $\sim 10 \mathrm{~kb}$ was also found in the cerebellum. The expression pattern of mGluR4 mRNA was rather specific. The high levels of the mRNA expression were observed in the cerebellum, thalamus, and olfactory bulb.
Only a trace amount of the mRNA was seen in the hippocampus.

In situ hybridization analysis indicated that mGluR 3 mRNA was expressed not only in neuronal cells but also in glial cells throughout the brain regions (Figs. $4 a, 5 a-c$ ). This mRNA was predominantly expressed in neurons of the cerebral cortex, thalamic reticular nucleus (Fig. $5 b$ ), and supraoptic nucleus, and granule cells in the dentate gyrus, and also in glial cells in white matter such as the corpus callosum (Fig. 5a) and anterior commissure. In the cerebellum, moderate expression was seen in Golgi cells (Fig. 5c). mGluR4 mRNA was more restrictedly distributed in neuronal cells (Figs. $4 b, 5 d-f$ ). Prominent expression of mGluR4 mRNA was observed in neurons of the internal granular layer of the main olfactory bulb (Fig. $5 d$ ), those of the thalamus (Fig. 5e), lateral septum, and pontine nucleus (Fig. $4 b$ ), and granule cells of the cerebellum (Fig. $5 f$ ). Only weak expression of mGluR4 mRNA was observed in the dentate gyrus and CA3 region of the hippocampus. No significant hybridization was observed in parallel control experiments using the same mGluR 3 or mGluR 4 probe in the presence of an excess of unlabeled probe (data not shown). Furthermore, in both mRNA analyses, a similar hybridization pattern was obtained with a different nonoverlapping probe derived from the mGluR3 or mGluR4 cDNA (data not shown). 


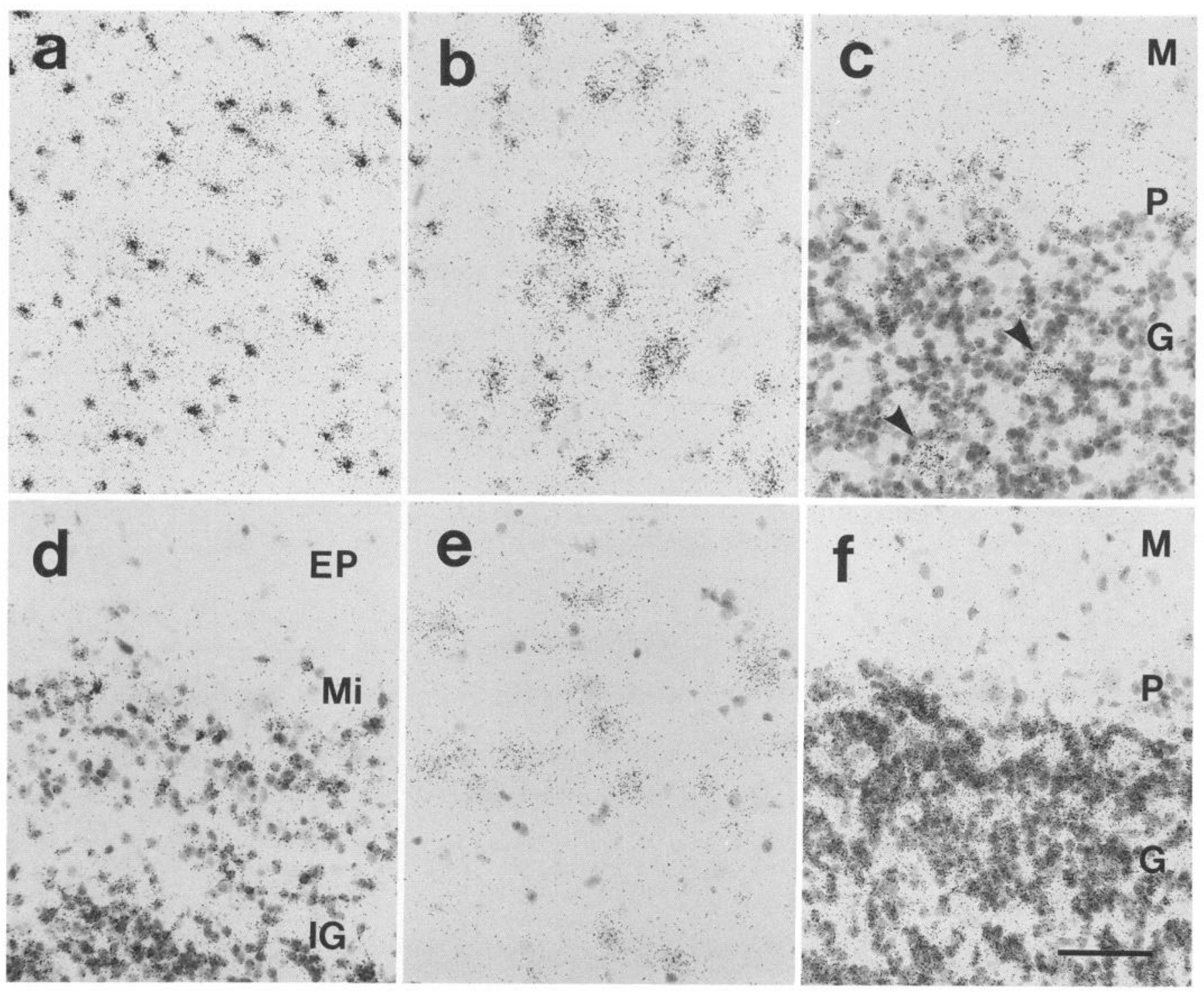

Figure 5. Localization of mGluR3 mRNA $(a-c)$ and mGluR4 mRNA $(d-f)$ in the adult rat brain by in situ hybridization. Bright-field photomicrographs of emulsion-dipped sections through the corpus callosum $(a)$, thalamic reticular nucleus $(b)$, cerebellar cortex $(c, f)$, olfactory bulb $(d)$, and ventrolateral thalamic nucleus $(e)$ are shown. In $a$, intense signals are seen in small glial cells. Arrowheads in $c$ indicate labeled Golgi cells. $M$, molecular layer; $P$, Purkinje cell layer; $G$, granular layer; $E P$, external plexiform layer; $M i$, mitral cell layer; $I G$, internal granular layer. Scale bar, $50 \mu \mathrm{m}$.

\section{Discussion}

This article reports the characterization of the signal transduction and agonist profiles of mGluR3 and mGluR4 and their expression patterns in the adult rat brain. mGluR3 resembles mGluR2 in both signal transduction and agonist selectivity. Similar to mGluR3, mGluR4 is coupled to the inhibitory cAMP cascade, but its agonist selectivity is totally different from not only mGluR $2 / m$ GluR 3 but also mGluR $1 / m$ GluR5. Interestingly, mGluR4 effectively and selectively interacts with L-AP4. It has previously been suggested by electrophysiological studies that there is a novel receptor that potently responds to L-AP4 (Koerner et al., 1981; Hori et al., 1982; Yamamoto et al., 1983; Lanthorn et al., 1984; Hearn et al., 1986). These studies indicated that L-AP4 suppressed neurotransmission in various synapses of the rat CNS, including the lateral entorhinal-dentate gyrus pathway and the lateral olfactory tract-prepyriform cortex pathway. L-AP4-sensitive responses have also been reported to occur in the mossy fiber-CA3 synapses of guinea pig, but not in the same synapses of rat (Lanthorn et al., 1984). The expression of mGluR4 mRNA is not necessarily high in neuronal cells projecting these neuronal pathways. However, the putative L-AP4 receptor has been shown to exhibit high stereospecificity for the L-isomer of AP4 and to interact moderately with L-serine$O$-phosphate (Cotman et al., 1986). Thus, the agonist profile of this receptor agrees well with that of mGluR4. Recent electrophysiological studies indicated that the L-AP4 receptor is involved in suppression of excitatory synaptic transmission by reducing glutamate release at a presynaptic site (Cotman et al., 1986; Forsythe and Clements, 1990; Baskys and Malenka, 1991). Thus, the L-AP4 receptor appears to represent a presynaptic autoreceptor. It is thus feasible that mGluR4 corresponds to the L-AP4 receptor at least at some of neuronal synapses and regulates glutamate neurotransmission by the action at presynaptic sites.

Another interesting system in which L-AP4 has been exten- 


\begin{tabular}{|c|c|c|c|c|}
\hline Subgroup & $\begin{array}{l}\text { Receptor } \\
\text { (amino acids) }\end{array}$ & $\begin{array}{l}\text { Signal } \\
\text { transduction }\end{array}$ & $\begin{array}{l}\text { Agonist } \\
\text { selectivity }\end{array}$ & mRNA expression sites ${ }^{a}$ \\
\hline \multirow[t]{3}{*}{ I } & $\begin{array}{l}\text { mGluR1 } \\
\text { (1199 or } 906)\end{array}$ & & & $\begin{array}{l}\text { Purkinje cells of cerebellum, mitral and } \\
\text { tufted cells of olfactory bulb, granule } \\
\text { cells of dentate gyrus, pyramidal cells of } \\
\text { CA2-CA4, neurons of thalamus }\end{array}$ \\
\hline & & $\begin{array}{l}\mathrm{IP}_{3} / \mathrm{Ca}^{2+} \\
\text { cascade }\end{array}$ & $\mathrm{QA}>$ Glu $\geq$ Ibo $>$ tACPD & \\
\hline & $\begin{array}{l}\text { mGluR5 } \\
(1171)\end{array}$ & & & $\begin{array}{l}\text { Neurons of striatum, cerebral cortex, and } \\
\text { internal granular layer of olfactory bulb; } \\
\text { granule cells of dentate gyrus; pyramidal } \\
\text { cells of CA1-CA4 }\end{array}$ \\
\hline \multirow[t]{3}{*}{ II } & $\begin{array}{c}\text { mGluR2 } \\
(872)\end{array}$ & & & $\begin{array}{l}\text { Golgi cells of cerebellum, granule cells of } \\
\text { dentate gyrus, neurons of cerebral cortex } \\
\text { and main and accessory olfactory bulb }\end{array}$ \\
\hline & & $\begin{array}{l}\text { Inhibitory } \\
\text { cAMP cascade }\end{array}$ & $\mathrm{Glu} \geq \mathrm{tACPD}>\mathrm{Ibo} \gg \mathrm{QA}$ & \\
\hline & $\begin{array}{l}\text { mGluR3 } \\
(879)\end{array}$ & & & $\begin{array}{l}\text { Neurons of cerebral cortex and thalamic } \\
\text { reticular nucleus, granule cells of dentate } \\
\text { gyrus, glial cells throughout the CNS }\end{array}$ \\
\hline III & $\begin{array}{l}\text { mGluR4 } \\
\text { (912) }\end{array}$ & $\begin{array}{l}\text { Inhibitory } \\
\text { cAMP cascade }\end{array}$ & L-AP4 $>$ Glu $>$ SOP & $\begin{array}{l}\text { Granule cells of cerebellum, neurons of } \\
\text { thalamus and internal granular layer of } \\
\text { olfactory bulb }\end{array}$ \\
\hline
\end{tabular}

$\mathrm{IP}_{3}$, inositol trisphosphate; QA, quisqualate; Glu, glutamate; Ibo, ibotenate; SOP, L-serine- $O$-phosphate.

a Only characteristic expression sites are described.

sively studied is within the retina. L-glutamate hyperpolarizes ON-bipolar cells and depolarizes OFF-bipolar cells in the retina. L-AP4 mimics the action of L-glutamate at ON-bipolar cells and selectively hyperpolarizes these cells (Nawy and Jahr, 1990, 1991). The hyperpolarization has been shown to result from lowering intracellular cGMP levels through the activation of G-protein-coupled glutamate receptor. The slight difference, however, has been reported for the pharmacological properties of the putative L-AP4 receptors in the hippocampal and retinal preparations (Peterson et al., 1991). It will thus be interesting to investigate whether mGluR4 or its related possible subtype is involved in hyperpolarization of ON-bipolar cells, and whether this receptor subtype is coupled to the cGMP cascade to regulate glutamate neurotransmission in bipolar cells.

Consistent with the sequence conservation betwecn mGluR2 and $\mathrm{mGluR} 3$, both receptors closely resemble each other in the signal transduction and agonist selectivity. Recently, tACPD, which is a potent agonist for $\mathrm{mGluR} 2 / \mathrm{mGluR} 3$, has been shown to inhibit cAMP formation in slices of the rat hippocampus (Schoepp et al, 1992). Furthermore, this compound showed suppressive effects on excitatory synaptic neurotransmission by the action at a presynaptic site (Baskys and Malenka, 1991). Thus, this receptor subgroup may also serve as a presynaptic autoreceptor. The mGluR3 subtype is, however, distinguished from other members of mGluRs by its prominent expression in glial cells throughout the brain regions. It has been reported that glial cells contain an mGluR that is linked to PI hydrolysis and shows an agonist selectivity different from that of mGluR3 (Pearce et al., 1986, Nicoletti et al., 1990). The discovery of the inhibitory cAMP cascade-linked mGluR in glial cells was un- expected, and the role of this receptor in glial functions will be interesting for further investigations.

Taking into account the results presented here, together with those reported previously (Abe et al., 1992; Aramori and Nakanishi, 1992; Tanabe et al., 1992), Table 1 summarizes the properties and expressions of five subtypes of the mGluR family. The five receptors can be classified into three subgroups. The first subgroup consists of $m$ GluR 1 and $m$ GluR 5 and is coupled to PI hydrolysis $/ \mathrm{Ca}^{2+}$ signal transduction. The most potent agonist for this receptor subgroup is quisqualate. The second subgroup is composed of mGluR2 and mGluR3 and is linked to the inhibitory cAMP cascade. $\mathrm{tACPD}$ is a very potent agonist for this subgroup. mGluR4 is classified as the third subgroup and is highly reactive with L-AP4. Although mGluR4 also inhibits cAMP accumulation, its low efficacy in inhibiting the cAMP formation may suggest that mGluR4 has yet another coupling system. The subtypes of the same subgroup show 60 $70 \%$ identity in the amino acid sequences and about $40 \%$ homology with different subgroups of the receptors. The properties characteristic of each subgroup are reflected by the high sequence similarity within the same subgroup of the receptors. Individual receptor subtypes, however, show specialized expression patterns in the CNS. Different subtypes of mGluRs may thus play differential roles in glutamate neurotransmission through the coupling to distinct intracellular signal transduction and different expressions in the CNS.

\section{References}

Abe T, Sugihara H, Nawa H, Shigemoto R, Mizuno N, Nakanishi S (1992) Molecular characterization of a novel metabotropic glutamate receptor mGluR5 coupled to inositol phosphate/ $\mathrm{Ca}^{2+}$ signal transduction. J Biol Chem 267:13361-13368. 
Aramori I, Nakanishi S (1992) Signal transduction and pharmacological characteristics of a metabotropic glutamate receptor, mGluR1, in transfected CHO cells. Neuron 8:757-765.

Baskys A, Malenka RC (1991) Agonists at metabotropic glutamate receptors presynaptically inhibit EPSCs in neonatal rat hippocampus. J Physiol (Lond) 444:687-701.

Collingridge GL, Singer W (1990) Excitatory amino acid receptors and synaptic plasticity. Trends Pharmacol Sci 11:290-296.

Cotman CW, Flatman JA, Ganong AH, Perkins MN (1986) Effects of excitatory amino acid antagonists on evoked and spontaneous excitatory potentials in guinea-pig hippocampus. J Physiol (Lond) 378:403-415.

Forsythe ID, Clements JD (1990) Presynaptic glutamate receptors depress excitatory monosynaptic transmission between mouse hippocampal neurones. J Physiol (Lond) 429:1-16.

Gilman AG (1984) G proteins and dual control of adenylate cyclase. Cell 36:577-579.

Graham FL, van der Eb AJ (1973) A new technique for the assay of infectivity of human adenovirus 5DNA. Virology 52:456-467.

Hearn TJ, Ganong AH, Cotman CW (1986) Antagonism of lateral olfactory tract synaptic potentials in rat prepyriform cortex slices. Brain Res 379:372-376.

Hori N, Auker CR, Braitman DJ, Carpenter DO (1982) Pharmacologic sensitivity of amino acid responses and synaptic activation of in vitro prepyriform neurons. J Neurophysiol 48:1289-1301.

Hollmann M, O'Shea-Greenfield A, Rogers SW, Heinemann S (1989) Cloning by functional expression of a member of the glutamate receptor family. Nature 342:643-648.

Houamed KM, Kuijper JL, Gilbert TL, Haldeman BA, O'Hara PJ, Mulvihill ER, Almers W, Hagen FS (1991) Cloning, expression, and gene structure of a $G$ protein-coupled glutamate receptor from rat brain. Science 252:1318-1321.

Koerner JF, Cotman CW (1981) Micromolar L-2-amino-4-phosphonobutyric acid selectively inhibits perforant path synapses from lateral entorhinal cortex. Brain Res 216:192-198.

Lanthorn TH, Ganong AH, Cotman CW (1984) 2-Amino-4-phosphonobutyrate selectively blocks mossy fiber-CA 3 responses in guinea pig but not rat hippocampus. Brain Res 290:174-178.

Masu M, Tanabe Y, Tsuchida K, Shigemoto R, Nakanishi S (1991) Sequence and expression of a metabotropic glutamate receptor. Nature 349:760-765.

Meldrum B, Garthwaite J (1990) Excitatory amino acid neurotoxicity and neurodegenerative disease. Trends Pharmacol Sci 11:379-387.

Monaghan DT, Bridges RJ, Cotman CW (1989) The excitatory amino acid receptors: their classes, pharmacology, and distinct properties in the function of the central nervous system. Annu Rev Pharmacol Toxicol 29:365-402.

Moriyoshi K, Masu M, Ishii T, Shigemoto R, Mizuno N, Nakanishi S (1991) Molecular cloning and characterization of the rat NMDA receptor. Nature 354:31-37.

Nawy S, Jahr CE (1990) Suppression by glutamate of CGMP-activated conductance in retinal bipolar cells. Nature 346:269-271.

Nawy S, Jahr CE (1991) cGMP-gated conductance in retinal bipolar cells is suppressed by the photoreceptor transmitter. Neuron 7:677683.

Nicoletti F, Magrì G, Ingrao F, Bruno V, Catania MV, Dell'Albani P, Condorelli DF, Avola R (1990) Excitatory amino acids stimulate inositol phospholipid hydrolysis and reduce proliferation in cultured astrocytes. J Neurochem 54:771-777.

Pearce B, Albrecht J, Morrow C, Murphy S (1986) Astrocyte glutamate receptor activation promotes inositol phospholipid turnover and calcium flux. Neurosci Lett 72:335-340.

Peterson NL, Thoreson WB, Johnson RL, Koerner JF, Miller RF (1991) Characterization of retinal and hippocampal L-AP4 receptors using conformationally constrained AP4 analogues. Brain Res 568:15-23.

Récasens M, Mayat E, Guiramand J (1991) Excitatory amino acid receptors and phosphonoinositide breakdown: facts and perspectives. In: Current aspects of the neurosciences, Vol 3 (Osborn NN, ed), pp 103-175. London: Macmillan.

Schoepp D, Bockaert J, Sladeczek F (1990) Pharmacological and functional characteristics of metabotropic excitatory amino acid receptors. Trends Pharmacol Sci 11:508-515.

Schoepp DD, Johnson BG, Monn JA (1992) Inhibition of cyclic AMP formation by a selective metabotropic glutamate receptor agonist. J Neurochem 58:1184-1186.

Tanabe Y, Masu M, Ishii T, Shigemoto R, Nakanishi S (1992) A family of metabotropic glutamate receptors. Neuron 8:169-179.

Ui M (1984) Islet-activating protein, pertussis toxin: a probe for functions of the inhibitory guanine nucleotide regulatory component of adenylate cyclase. Trends Pharmacol Sci 5:277-279.

Urlaub G, Chasin LA (1980) Isolation of Chinese hamster cell mutants deficient in dihydrofolate reductase activity. Proc Natl Acad Sci USA 77:4216-4220.

Watkins JC, Krogsgaard-Larsen P, Honoré T (1990) Structure-activity relationships in the development of excitatory amino acid receptor agonists and competitive antagonists. Trends Pharmacol Sci 11:2533.

Yamamoto C, Sawada S, Takada S (1983) Suppressing action of 2-amino-4-phosphonobutyric acid on mossy fiber-induced excitation in the guinea pig hippocampus. Exp Brain Res 51:128-134. 